\title{
The Impact of Building Regulation Contravention on Rapid Urbanisation: Case of Kano Metropolis
}

\author{
Sani Khalil Ibrahim, fnia ${ }^{1}$
}

\begin{abstract}
An increasingly urbanizing world has made building regulation central to the organized development of cities world-wide. It is noted that half of the world's population is now living in cities. The world urban population is expected to increase by $84 \%$ by 2050 , from 3.4 billion in 2009 to 6.3 billion and will happen in developing countries. Also projected in the next 20 years, over $95 \%$ of this population growth will occur in urban areas. Kano is among the fast urbanizing cities in the West African sub region. This paper focuses on the implication of building regulation contravention in Kano metropolis and its impact on the sustainability in mixed land-use areas. It identifies and documents the key drivers of contravention. The findings are expected to create the platform for developing a conceptual framework that might improve compliance to sustainable development regulation regime in Kano metropolis. The significance of the findings is expected to form the foundation towards development compliance procedures for a more sustainable urbanization process in the sub-region. Like Kano, Cities play vital role globally and nationally, as economic, social, cultural and political centers. To successfully achieve this, urbanization should sustainably be driven. Data was collected through Visual survey, interview and questionnaires and subjected to descriptive analysis. Preliminary findings indicate negative perception of current building approval and enforcement procedures in Kano.
\end{abstract}

Keywords: Building Regulations, Contraventions, Sustainable Development, Compliance Procedures and Enforcement

\section{Introduction}

Urbanization as a phenomenon in the $21^{\text {st }}$ century is recorded all over the world and is directly linked with increase in population. The growth of cities due to population increase results in the demand of buildings for various activities (Mobogunje, 1968). Some measures of control for such developments are needed (Bashorun, 2003). This informed the physical development control measures such as urban landuse, zoning and building regulations (Uloko and Agbonoga, 2005).

The rapid of urbanization growth in most nations especially the developing countries seem to overwhelm their respective governments, hence, battling to cope with the challenges posed by same. Moreover, basic infrastructure and services are evidently not adequate to the residents due to non adherence to urban growth and development. These urban issues negate the well-being of Kano city communities, Nigeria's second largest city as recorded by the National Population Census in 2009. As opined by Opoko and Oluwatayo(2014) the developing world is currently grappling with the challenges of urbanization especially in the area of housing provision, which appears to motivate development control contraventions. The Building Regulation Contravention therefore affects sustainable urban development especially in Kano metropolis with fast population growth and rapid urbanization. 
The paper is in five (5) sections. Following this introduction is the problem statement that outlines the research issues relevant to the impact of building regulations contraventions on rapid urbanisation, and the effects of such actions on the mixed land use areas of Kano metropolis. Means of data collection and analysis were treated in the third section, i.e. the research design. The fourth part is the study's outcome, such as the consequences of contraventions on the affected areas. Section five concludes the paper with recommendations on the sustainable building regulations through creation of awareness and enforcement.

\section{Literature Review}

\subsection{Urbanistion as a process}

The world urban population is expected to increase by $84 \%$ by 2050 , from 3.4 billion in 2009 to 6.3 billion and will happen in developing countries. Also projected in the next 20 years, over $95 \%$ of this population growth will occur in urban areas especially Asia and Africa. The notable African Country is Nigeria where Lagos is followed by Kano in terms of population growth.

Further, the world population as reported by United Nations (World population: 201906-26) is about 7billion which implies strong correlation with urbanisation due demand in food, education, health, social services, housing, infrastructure and so on that are needed to cater for this teeming population.

\subsection{Regulation and sustainabilty}

As opined by Ibrahim (2013), that Buildings provided in accordance with identified landuse makes architecture the core component of urban landuse. Therefore Building Regulations and Bye-laws are provided to guide building development. Their provision therefore is for the purpose of standards, safety, security etc (Baden-Powell, 2008) hence it is for control of physical development activities in a balanced way (Popoola, 2002).

As observed building plan approvals are obtained as a first step to commence of physical development, though not strictly observed during construction and post construction stages. The question that readily comes to mind is where does the problem emanate from? Is it from the implementing authorities or implementation of the approved building designs? And it should be noted that lack of control of physical development of the environment simply results into, as noted by Popoola (2002), in disorderly development, incompatible landuse, and inadequate access to various landuses and inadequate provision of amenities. This has had negative effect on architecture (building design approval) infrastructure and facilities within such environment.

As regards to the concept of sustainability in relation to urbanization, the basic principles as highlighted by Michael Ben Eli (http://www.sustainabilitylabs.org/page /sustainability-five-core-principles) are: i. The Material Domain: Constitutes the basis for regulating the flow of materials and energy that underlie existence, ii. The Economic Domain: Provides a guiding framework for husbanding and managing wealth, iii. The Domain of Life: Provides the basis for appropriate behavior in the biosphere, iv. The Social Domain: Provides the basis for social interactions and v. The Spiritual Domain: 
Identifies the necessary attitudinal orientation and provides the basis for a universal code of ethics. Summarily, sustainability is in relation to reduction of usage of fossil fuel for energy purposes, economy and social wellbeing of the general community. In general it is to do with control of actions that will have negative consequences to our environment and control of waste through re-usage.

Our Cities therefore play vital role globally and nationally, as economic, social, cultural and political centers. Kano represents these key aspects hence regarded as centre of commerce and can be linked with the increase in population that leads to rapid urban growth while the impact of building regulation contravention is to certainly likely lead to negating of sustainability principles.

\subsection{Causes of contravention in Kano Metropolitan Rea}

The causes of contraventions as exemplified by Ibrahim (2013) could be due to process of architectural building plans, zoning regulations that did not consider the needs and requirements of the people, challenges in relation to building plan approval process, lack of enforcement of the offenders and non appreciation of negative consequences of contravention.

Basically, Kano Metropolis is divided into three planning areas comprising of traditional walled city that was not under any development control activity; second, unplanned areas found at the periphery of the city wall, so also along major roads out of Kano and neighbouring villages already enveloped by the growth of metropolis. The areas are characterized by lack of proper infrastructural facilities and not laid out or properly zoned. The third is the planned area with proper planned landuse and zoning regulations while development in any form must be subjected to building plan approval by the relevant authority referred to as Kano State Planning and Development Authority (KNUPDA).

Kano State comprises of 44 Local Government Areas (LGA) and the metropolitan is composed of Seven LGA's, namely: Kano Municipal, Dala, Fagge, Nassarawa, Ungogo, Kumbotso and Tarauni. The Planning Authority, KNUPDA, was established in 1975 as Kano Metropolitan Board to Urban Development Board, Kano State Urban Environmental Planning and Protection Agency and now Kano State Urban Planning and Development Authority with a mandate to coordinate and control physical development of Kano Metropolis hence this connotes control of all building developments.

The Metropolitan Kano 2000 master plan and its review provided management of land as a resource hence provision of layouts to cater for various types of developmental activities. Therefore any development within a layout must have an Architectural Building Plan (ABP) while the basis of approval of ABP is the Building Regulations of 1988 for the state (Kano State Government, 1988). This provides the assessment criteria for contravention so also the impact of same on rapid urbanization of Kano Metropolis.

\section{Materials and Methods}

This is research is based on secondary data source documented by KNUPDA that relies on quantitative research approach for systematic empirical investigation of a 
social phenomenon through statistical techniques (Ibrahim \&Raji, 2019; Nor, 2009). The data collected from Archives of KNUPDA was the total number of applications received and those approved annually from 2014 to 2018. Questionnaires were distributed directly and online, through emails, to professionals who usually apply for approvals on behalf of their clients. A total of 24 responses were received and analysed using percentile. Descriptive statistics was employed to establish the level of impact on building regulation contravention on rapid urbanization in Kano Metropolis.

It should be noted nonetheless that there are a few differences with building regulations in different states in Nigeria so also the level of awareness, hence conclusion for the whole country cannot be drawn from this research, therefore there is need for further research to include wider population.

\section{Data Analysis}

The basis of analysis for this research was on the generated data gathered from KNUPDA and the Questionnaire administered to Consultants who normally apply for building plan approval on behalf of their clients. Below is a table showing applications received and those approved annually for period of five years

Table 1: showing number of applications received, approved and denied approval

\begin{tabular}{|c|c|c|c|c|c|c|}
\hline s/no Year & $\begin{array}{c}\text { No. of } \\
\text { Applications } \\
\text { Received }\end{array}$ & $\begin{array}{c}\text { No. of } \\
\text { Applications } \\
\text { Approved }\end{array}$ & $\begin{array}{c}\text { Percentage of } \\
\text { Applications } \\
\text { Approved }\end{array}$ & $\begin{array}{c}\text { No. of } \\
\text { Applications } \\
\text { Denied }\end{array}$ & $\begin{array}{c}\text { Percentage of } \\
\text { Denied } \\
\text { applications }\end{array}$ \\
\hline 1 & 2014 & 1196 & 586 & $49 \%$ & 610 & $51 \%$ \\
\hline 2 & 2015 & 1392 & 720 & $51.7 \%$ & 672 & $48.3 \%$ \\
\hline 3 & 2016 & 1499 & 668 & $44.6 \%$ & 831 & $55.4 \%$ \\
\hline 4 & 2017 & 1237 & 544 & $44 \%$ & 693 & $56 \%$ \\
\hline 5 & 2018 & 1060 & 433 & $40.8 \%$ & 627 & $59.2 \%$ \\
\hline & Total & 6384 & 2951 & Avrg. $46.02 \%$ & 3433 & Avrg. 53.98 \\
\hline
\end{tabular}

Source: Kano State Planning and Development Authority, 2019

\section{Histogram}

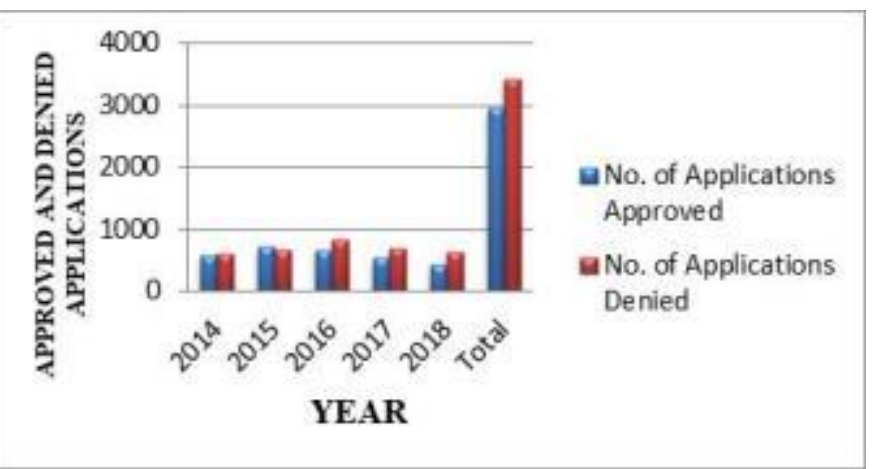

Fig. 1 showing no. of applications approved and denied annually from 2014 to 2018

Source: Author's field work, 2019 


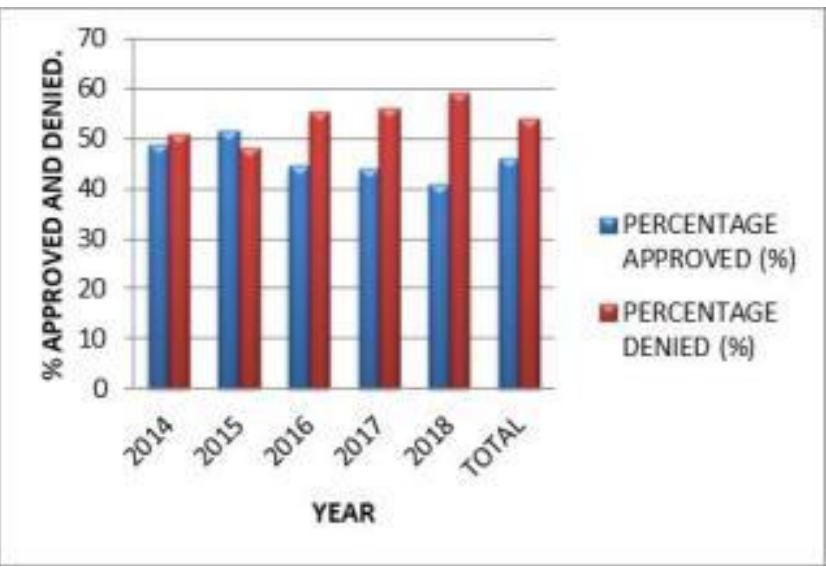

Fig.2 Showing percentage of approved and denied applications from 2014 to 2018

Author's field work, 2019

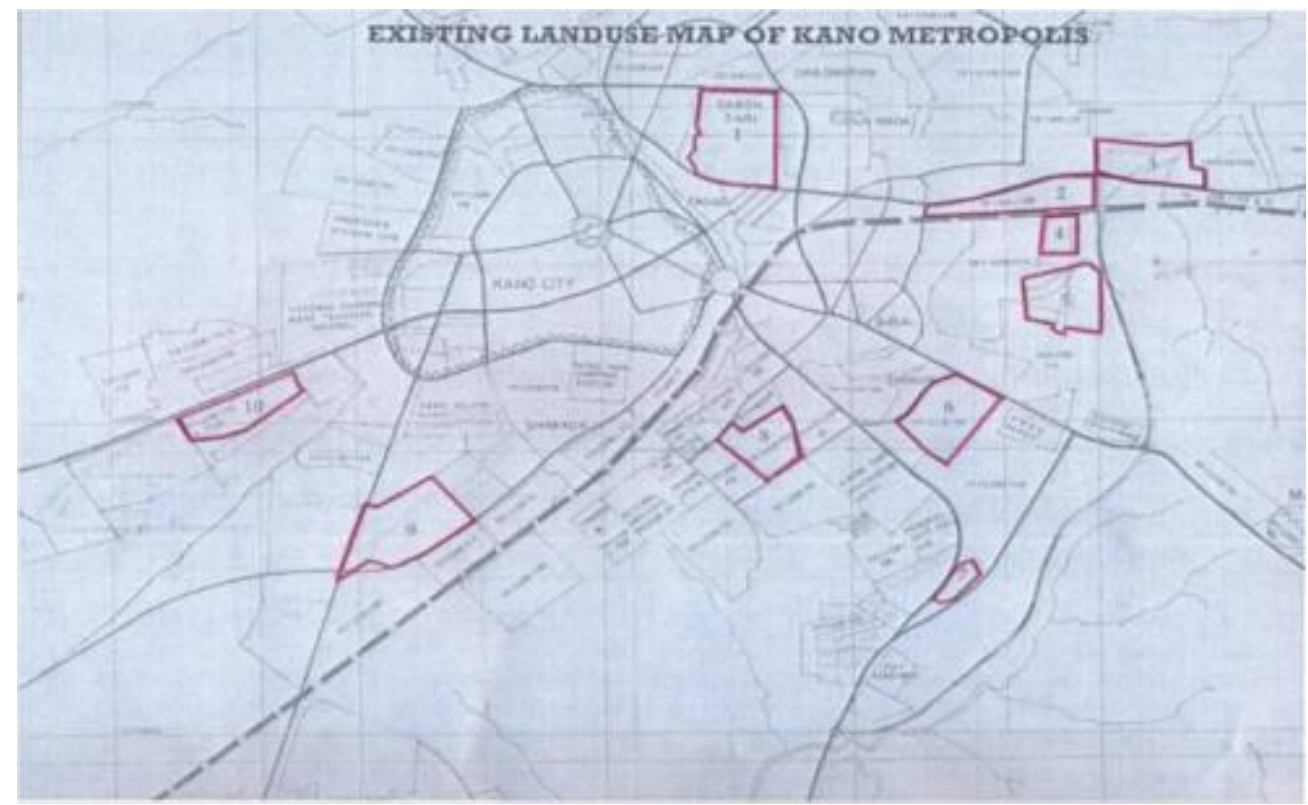

Fig 3.0 Existing Land use Map of Kano Metropolis

Source: Kano State Planning and Development Authority, 2012 \&JIbrabim, 2013

From the above data, the total number of application for the five year period was 6384 while number of approved applications were 2951 and those denied approval for a number of reasons were 3433 this reflected a percentage of 46.02 and 53.08 respectively. This can be compared to records from Ibrahim (2013) where from 1990 to 2009, 1348 applications were received ie $255 \%$ increase in just five years.

The relevance of the data table 1.0 is to analyse same to provide the answers to some aspect of the rapid urbanization in relation to building regulation contravention. This is in line with effectiveness of the planning authority to grant or deny approval. Therefore 
the following is to form the basis for analysis:
A. Application for Building approval from 2014 to 2018
1. Trend- how could it be explained to elucidate points?
2. What does the total of applications approved and denied reflect?
B. Denials of Building approvals
1. Trend- What was observed over the years?
2. Total- Group A: Approved applications
Group B: Denied applications

In order to make deduction from table $1.0, \mathrm{~A}+\mathrm{B}$ is to be combined and same connotes comparative study in terms of approval/denial.

Further, this will imply:

i. Show the increase in application for building approval

ii. Questionnaire is to elucidate reasons for contravention of building regulations, impact on economy, environment, building services, quality of habitability and aesthetics.

From the table 1.0 and the histogram fig. $1 \& 2$, the increase in the applications could be an indicator of the public becoming more aware of the activities of the planning authority. This implies that there is increase in demand for spaces for activities due increase in population as adduced by various researchers. However, the denials are equally on the high side about 50\% which implies the applicants either do not follow the guidelines provided by the building regulation of Kano State or the issue of complicity and sharp practices of the authority staff. It could also be due to lack of proper awareness or zoning issue.

\section{Basis of Analysis from Questionnaire}

The nature of contraventions based the questionnaire result was ranked according to the number of respondents are as follows:

i.Set back not adequate- 6; ii. Room size not adequate-2; iii. Landuse does not conform to approved-2; iv. Parking space not adequate-2; v. Building plan not approved-1; vi. Building height not as recommended-2; and vii. Others (specify)-0. The nature of contraventions with highest number of respondents is the set back not adequate or according to standards accounting about $25 \%$ while others account about $8 \%$. This implies that set back issue will affect ventilation, natural lighting, indoor comfort and privacy. The resultant effect of this is quality of life in the community; Kano Metropolitan will be affected so also increase in energy consumption.

The respondents all agreed that there is serious impact on the economy as building regulation is contravened with 22 yes and 0 -no while 2 students did not recommend anything. Therefore the contravention impact on economy, with 100\% responses, will consequently be in respect any likely removal of structure that failed to satisfy the standards, cost in provision of energy to maintain indoor quality and ultimately sustainable urban growth and development.

The reasons for contravention of building regulation in Kano metropolis are adduced as i. Lack of awareness by the public- 5; ii. Sharp practices by the planning authority staff-5, iii. Non-enforcement of penalties by the authority-4; and iv. failure to comply with zoning-1. It can be deduced that the reasons due lack of awareness and sharp practices 
by officers with about 30\% each implies that urban growth and development will be affected as development will be haphazard and this is equally the consequence of non enforcement of penalties and zoning.

The building regulation contravention impacts negatively on the following: i. Environment-6; ii. Building Services- 6; iii. Quality of Habitability-8; and iv. Aesthetics -4 . The consequences of impact where quality of habitability is as high as $33 \%$, Environment and building services with $25 \%$ each while aesthetics is the lowest with $12.5 \%$ hence these imply that urban development will suffer consequence of difficult planning by government ion provision of infrastructure, quality will affect health and wellbeing of the public in Kano Metropolis. Therefore, cost in service provision will increase hence will affect less volume of service and sustainability to create better living condition will be affected.

As a strategy by the planning authority, the building plan approval process is an important tool while the requirement must be within the Nigeria's extant laws and this is exemplified by Ibrahim (2013), Ibrahim \&Gyoh (2014) as building plan requirement process in Nigeria as a synthesis thereby taking a number of other regulations from some States into consideration

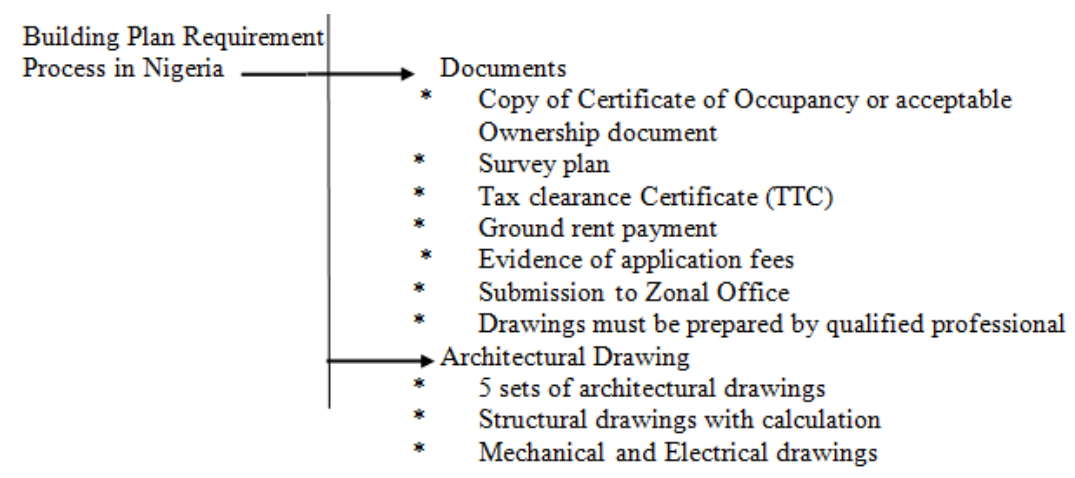

Fig 4 : Synthesis of Architectural Building Plan Approval process in Nigeria

Source: Development Control Practices

The data collected from KNUPDA and the responses from consultants it can be deduced that both corroborated each other.

\section{Conclusion and Recommendation}

The Impact of building regulation contravention in Kano Metropolis where rapid urbanization is the hallmark of the city due to population increase requires, based on data analysed, some strategies to plan the future of the city to accommodate the population envisaged by 2050. Quality of habitability, Environmental issues, building services and aesthetics are negatively affected by the contravention of building regulation. It should be noted that the consequences will be haphazard urban development and growth, provision of infrastructure will be difficult hence quality of life for the general public in Kano Metropolis will be affected negatively especially the lack 
of enforcement by the authority and lack of awareness by the public. This therefore connotes effect on sustainable urbanization.

The recommendation to these negative issues and consequences aforementioned is to ensure creation of integrated strategy through sustainable linkages with communities. Create public awareness, through advocacy programmes, of the consequences of contravention of building regulation so also enforcement of proper penalties against erring public by the government through its agent, KNUPDA. Dedicated and qualified staff are needed to be in the service of KNUPDA, with good character, honest and difficult to be compromised during conduct of their duties. Consultants should educate their clients from design stage of the need to avoid contravention in any form of it.

\section{Acknowledgement}

The Author acknowledges and appreciates the financial support by Bayero University Kano and Tertiary Education Trust Fund (TETFUND), Nigeria.

\section{References}

Baden - Powell. C, Hetreed, J, and Ross, A. (2008, 3rd ed), ArchitectsPocket Book, Elsevier Ltd, Linacre House Jordan Hill, Oxford OV2 8Dp, U.K.

Bosorun J.O, (2003), Basic Elements of Urban and Regional Planning,Shalom Publishers, 92 Ijorun Street Akure, Ondo, Nigeria. (Page $1-11$ )

Ibrahim, S.K and Raji, A.U, (2018), Sustainable Green Building Public Awareness for Clients Benefit's Realisation in Kano Nigeria, SAVANNA, A Journal of the Environment and Social Science, Vol. 24, No. 2, Aril 2018

Ibrahim, S.K and Gyoh. L, (2018), Sustainable Development Control Practicesand Its Impact ON Sustainable Urbanisation in Kano City, Nigeria. SAVANNA, A Journal of the Environment and Social Science, Vol. 24, No. 3, October, 2018. P219-223.

Ibrahim,S.K. (2013), Assessment of the Impact of Contraventions of Building Regulations on the Architecture of Mixed Landuse Areas of Kano Metropolis, Nigeria (1990-2009), unpublished PhD dissertation, 2013

Kano State Environment Planning and protection Agency (1988), Building Regulations, Kano State Government Printing Press.

Mabogunje, A.M (1968), Urbanization in Nigeria, University of London Press Ltd, London.

Michael Ben Eli (http://www.sustainabilitylabs.org/page/sustainability-five-core-principles

Ogu, V.I and Ogbuozobe, J.E (2001). Housing Policy in Nigeria: Towards Enablement of Private Housing Development. Habitat International 25 (2001): 473-492

Okpoechi, Chinwe (2006), Urban Design Issues in the provision of publicinfrastructure and improvement of the Quality of Nigeria cities, Urban Design Research Team, Urban Environment sustainability, International and responses, Editors, J.A. Fadamiro, J.A.B. Olujimi, and A.M.O Atolagbe; Shalom Publishers, Akure, Nigeria .

Popoola, J.O (2002), Obtaining Permission for Development: Present Situation and a Way Forward for Kaduna State, Control in Local Government Area of Kaduna State: The Way Forward, Kaduna Nigeria. (Page 1 - 15).

Uloko, C.E., and Agbonoga, J.E. (2005), An essential Handbook forPbysical Planners, Alex Publication, AK. 23 Wushishi Road, Kaduna.

World Population. (2019-06-26). Retrieved 2019-06-30, from http://worldpopulationreview.com /continents/world/ 